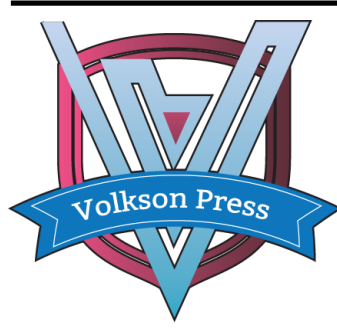

Contents List available at VOLKSON PRESS

\title{
THE APPLICATION OF BP NEURAL NETWORK IN STUDENTS' EVALUATION
}

\author{
Kaixin Li, Shixin Li*, Chaonan Fan, Yang Cao, LingLin Li \\ College of Electronic Engineering, Tianjin University of Technology and Education, Dagu South Road, Tianjin, China
}

This is an open access article distributed under the Creative Commons Attribution License, which permits unrestricted use, distribution, and reproduction in any medium, provided the original work is properly cited

\section{ARTICLE DETAILS}

\section{Article History:}

Received 26 June 2018

Accepted 2 July 2018

Available online 1 August 2018

\section{ABSTRACT}

\begin{abstract}
Student's examination evaluation is a more complex and multi-factor nonlinear process. The traditional evaluation method is difficult to objectively and fairly reflect the student's learning effect. Through establishing the model of student examination evaluation system based on BP neural network and Collect students' scores in one class according to index as samples of network training, this paper establishes BP neural network and simulates it through MATLAB software. Through the modification of the network weight parameter, the achievement error obtained after training is controlled to be acceptable. The results show that the student test evaluation model based on BP neural network can overcome the interference of various human factors on student performance, increase the reasonableness of the evaluation work.
\end{abstract}

KEYWORDS

Examination evaluation of students, BP neural network, MATLAB simulation.

\section{INTRODUCTION}

Students' examination evaluation is an important part of the education system. The accuracy of the evaluation results is directly related to the cultivation of school students. How to assess students' learning development more accurately and more reasonably is a major theoretical and practical issue in the process of in-depth education reform and comprehensive advancement of quality education. Based on a study, it is also a new round of national one of the directions of educational reform [1]. However, in the actual assessment of students, there are many factors that affect the evaluation, and each factor may also have relevance. This makes it difficult for us to use a linear mathematical formula or a simple weighted average to express the results of student assessment. Therefore, it is necessary to find a simple and objective evaluation method of learning effects.

\section{BP NEURAL NETWORK}

BP neural network is a multi-layer feedforward network trained by error back propagation algorithm. It is composed of multiple neurons connected together by certain rules, which can well simulate the nonlinear system and realize arbitrary nonlinear mapping between input and output. The value of each indicator attribute used for student test evaluation is taken as the input vector of the BP network model, and the evaluation result is taken as the output of the BP network model. Use enough scientific samples to train the network for adaptive learning. In this way, the BP network automatically adjusts the weight coefficient values and thresholds until it reaches an accurate internal representation of knowledge. According to a research, the value of each index of student learning evaluation is input into the trained BP neural network model, and the evaluation result of student learning effect is obtained [2]. This method can effectively avoid the subjectivity of evaluation, achieve qualitative and quantitative effective integration, and ensure the objectivity and stability of evaluation.

\section{STUDENT EXAMINATION EVALUATION MODEL BASED ON BP NEURAL NETWORK}

\subsection{Construction of evaluation index system}

This paper is based on the study of the author's school, According to the principles of systematicness, pertinence, practicality and independence. refer to the standards of other fraternal institutions, summarize the factors that may affect students' learning effect and analyze their impact. Select classroom performance, extension and expansion, professional practice, achievement assessment of 4 first level indicators. Research showed attendance, discipline and other 12 second level indicators to build evaluation index system, and according to the impact of indicators on student achievement, reasonable distribution of scores [3]. The examination evaluation index system are shown in Table 1.

Table 1: Examination evaluation index system

\begin{tabular}{|c|c|c|c|c|c|}
\hline $\begin{array}{l}\text { First level } \\
\text { index and } \\
\text { Proportion }\end{array}$ & $\begin{array}{l}\text { Second } \\
\text { index } \\
\text { Proportion }\end{array}$ & $\begin{array}{r}\text { level } \\
\text { and }\end{array}$ & $\begin{array}{l}\text { First level } \\
\text { index and } \\
\text { Proportion }\end{array}$ & \multicolumn{2}{|c|}{$\begin{array}{l}\text { Second level index } \\
\text { and Proportion }\end{array}$} \\
\hline \multirow{3}{*}{$\begin{array}{l}\text { Performan } \\
\text { ce in class } \\
(15 \%)\end{array}$} & $\begin{array}{l}\text { Attendanc } \\
\mathrm{e}\end{array}$ & $\begin{array}{l}35 \\
\%\end{array}$ & \multirow{3}{*}{$\begin{array}{c}\text { Profession } \\
\text { al practice } \\
(25 \%)\end{array}$} & $\begin{array}{l}\text { Operation } \\
\text { specification }\end{array}$ & $\begin{array}{l}15 \\
\%\end{array}$ \\
\hline & discipline & $\begin{array}{l}40 \\
\%\end{array}$ & & Skill mastery & $\begin{array}{l}30 \\
\%\end{array}$ \\
\hline & $\begin{array}{l}\text { Interactio } \\
\mathrm{n}\end{array}$ & $\begin{array}{l}25 \\
\%\end{array}$ & & $\begin{array}{l}\text { Comprehensi } \\
\text { ve } \\
\text { application }\end{array}$ & $\begin{array}{l}55 \\
\%\end{array}$ \\
\hline \multirow{3}{*}{$\begin{array}{l}\text { Extension } \\
\text { and } \\
\text { expansion } \\
(10 \%)\end{array}$} & $\begin{array}{l}\text { Reading } \\
\text { volume }\end{array}$ & $\begin{array}{l}40 \\
\%\end{array}$ & \multirow{3}{*}{$\begin{array}{l}\text { Achieveme } \\
\text { nt } \\
\text { assessmen } \\
\text { t }(50 \%)\end{array}$} & $\begin{array}{l}\text { Examination } \\
\text { performance }\end{array}$ & $\begin{array}{l}10 \\
\%\end{array}$ \\
\hline & $\begin{array}{l}\text { Scientific } \\
\text { research } \\
\text { innovatio } \\
\mathrm{n}\end{array}$ & $\begin{array}{l}40 \\
\%\end{array}$ & & $\begin{array}{l}\text { Ordinary } \\
\text { performance }\end{array}$ & $\begin{array}{l}20 \\
\%\end{array}$ \\
\hline & $\begin{array}{l}\text { Competiti } \\
\text { on results }\end{array}$ & $\begin{array}{l}20 \\
\%\end{array}$ & & $\begin{array}{l}\text { Final } \\
\text { assessment }\end{array}$ & $\begin{array}{l}70 \\
\%\end{array}$ \\
\hline
\end{tabular}

\subsection{Acquisition of sample data}

The quality of training samples directly determines the quality of the network model, so the collection of training samples should be paid special attention to. In the index, the classroom performance, professional practice and performance assessment are recorded by the teachers' regular records and achievement assessment. The indicators of extension and development require supervision under the guidance of the head teacher. Select 6 students who have principles and actively serve the class group to form an evaluation team. The evaluation team should collect all 
the materials related to the index content, evaluate the students objectively and impartially and score independently, and finally get the input data of the index.

\subsection{The establishment of BP network model}

\subsubsection{Determine the number of network layers}

The BP neural network can contain one or more hidden layers. It is proved by theory that a single hidden layer network can realize arbitrary nonlinear mapping by properly increasing the number of neurons. A research selects a three layer BP neural network with a single hidden layer [4]. The structure of the BP neural network is shown in Figure 1.

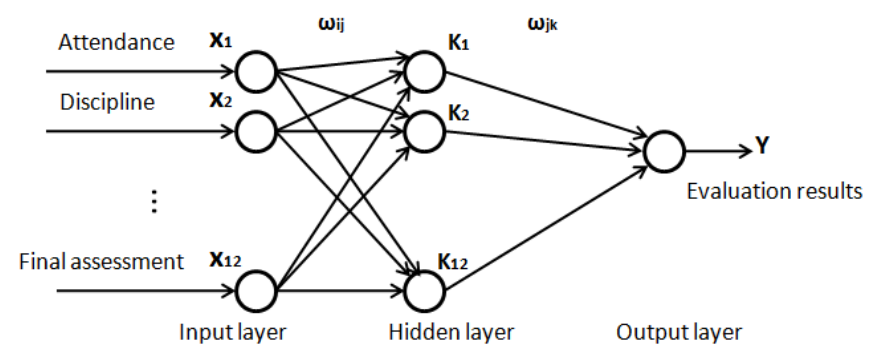

Figure 1: BP neural network structure

\subsubsection{Design of input and output layers}

There are 12 indicators in the evaluation system, so the number of nodes in the input layer ' $n$ ' is 12 . The result of evaluation is the only output of the network, so the number of neurons in the output layer ' $\mathrm{m}$ ' is 1 .

\subsubsection{Determine the number of hidden layers}

The number of hidden layer nodes has great influence on the performance of BP neural network. Generally, the number of hidden layer nodes can bring better performance, but it may cause the longer training time. In theory, there is not an ideal analytic formula to determine the reasonable number of hidden layer nodes. In this paper, we use empirical formula $M=\sqrt{\mathrm{n}+\mathrm{m}}+\mathrm{a}$ to give estimates. Among them, ' $\mathrm{a}$ ' is a constant between $[0,10]$. After testing, the selection of the number of hidden layer nodes in this paper is 6 .

\subsubsection{Selection of activation functions}

In this paper, linear activation function is used as the activation function of output layer, and the function form is 'purelin'. The expression is:

$$
f(x)=x
$$

The hyperbolic tangent Tan-Sigmoid function is used as the hidden layer activation function, and the function form is 'Tansig'. The expression is:

$$
f(x)=\frac{2}{1+e^{-x}}-1 \quad(-1<f(x)<1)
$$

\subsubsection{Selection of training methods}

The training method selects the momentum BP algorithm with variable learning rate, and the training function is 'traindx'. This method can improve the convergence rate and enhance the stability of the network.

\section{APPLICATION EXAMPLES AND RESULTS ANALYSIS}

\subsection{Acquisition of sample data}

According to the requirements, the author randomly selected a course for one semester of 25 students in a class of electronic information majors in our school to track records for one semester. The sample data section was shown in Table 2. Student achievement is strictly calculated according to the proportion of the index: if the student's final score is 89 points, multiply it by $70 \%$, and the final result will be 62 points. The experts score in the form is calculated by the ratio of the sample data according to the index system.

The first 20 sets of data in the form are used as learning data for training the learning network model. The latter 5 sets of data are test samples, which are used to compare training errors to determine the performance of the obtained network models.

Table 1: Title of the Table

\begin{tabular}{|l|l|l|l|l|l|l|l|l|l|l|}
\hline & 1 & 2 & 3 & $\ldots$ & 20 & 21 & 22 & 23 & 24 & 25 \\
\hline Attendance & 32 & 30 & 35 & $\ldots$ & 24 & 33 & 35 & 35 & 35 & 31 \\
\hline discipline & 36 & 32 & 38 & $\ldots$ & 28 & 33 & 36 & 40 & 37 & 38 \\
\hline Interaction & 14 & 16 & 22 & $\ldots$ & 5 & 16 & 16 & 14 & 14 & 18 \\
\hline Operation specification & 14 & 14 & 15 & $\ldots$ & 12 & 13 & 15 & 13 & 15 & 15 \\
\hline Skill mastery & 26 & 25 & 28 & $\ldots$ & 22 & 24 & 26 & 26 & 27 & 28 \\
\hline Comprehensive application & 49 & 48 & 51 & $\ldots$ & 46 & 45 & 47 & 53 & 44 & 48 \\
\hline Reading volume & 32 & 28 & 34 & $\ldots$ & 36 & 34 & 38 & 38 & 33 & 31 \\
\hline Scientific research innovation & 33 & 27 & 31 & $\ldots$ & 28 & 35 & 25 & 29 & 30 & 23 \\
\hline Competition results & 18 & 12 & 20 & $\ldots$ & 12 & 18 & 12 & 8 & 8 & 13 \\
\hline Examination performance & 10 & 10 & 10 & $\ldots$ & 10 & 8 & 10 & 8 & 10 & 10 \\
\hline Ordinary performance & 19 & 16 & 18 & $\ldots$ & 18 & 13 & 15 & 15 & 15 & 18 \\
\hline Final assessment & 67 & 62 & 62 & $\ldots$ & 55 & 57 & 49 & 69 & 57 & 51 \\
\hline Experts score & 91 & 84 & 91 & $\ldots$ & 78 & 80 & 80 & 90 & 83 & 82 \\
\hline
\end{tabular}

\subsection{Training of sample data}

The new function is used to create a BP neural network with 12 inputs, 1 outputs and 6 hidden layer nodes. The initial learning rate is 0.01 , the intermediate result cycle is 5000 , and the maximum training frequency is 5000 times. The accuracy of the network is $10^{-9}$ times. The value of momentum factor in the network is 0.9. The specific programming is as follows:

$[\mathrm{pn}, \min p, \operatorname{maxp}, \mathrm{tn}, \operatorname{mint}, \operatorname{maxt}]=\operatorname{premnmx}(\mathrm{P}, \mathrm{T}) ; \quad$ \%Normalization of data

net=newff(minmax(pn),[12,6,1],\{'tansig','tansig','purelin'\},'traingdx'
net.trainParam.show=5000; \%The period of the intermediate result net.trainParam.lr $=0.01 ; \quad$ \%Learning rate net.trainParam.mc $=0.9 ; \quad \%$ momentum factor net.trainParam.epochs $=5000 ; \quad \%$ Maximum training times net.trainParam.goal=1e-9; \%The accuracy of training to be achieved [net,tr]=train(net,pn,tn); \%Training BP network

$\mathrm{p} 2 \mathrm{n}=$ tramnmx(ptest,minp,maxp); \%Normalization of test data an=sim(net,p2n);

[a]=postmnmx(an,mint,maxt); \%Reverse normalization of data error=T1-a; \%Error vector

In the program, $\mathrm{P}$ represents the first 20 sets of data sets for the network training, T represents the expert score set of the first 20 sets of data, prest represents the first 30 sets of sample data sets, a represents the initial training result of the network, and gets the final training result after 
reverse normalization a. 30 sets of expert score data $\mathrm{T} 1$ and network training result a are subtracted to get the training error of the network.

\subsection{Training results and analysis}

The training results of the neural network after matlab training are shown in figures 2, 3, 4, and 5. From Figure 2, we can see that when the number of training steps is 560 steps, the accuracy of learning is achieved, and the errors are basically in line with the requirements. The network convergence is good, and the training time is less than a second.

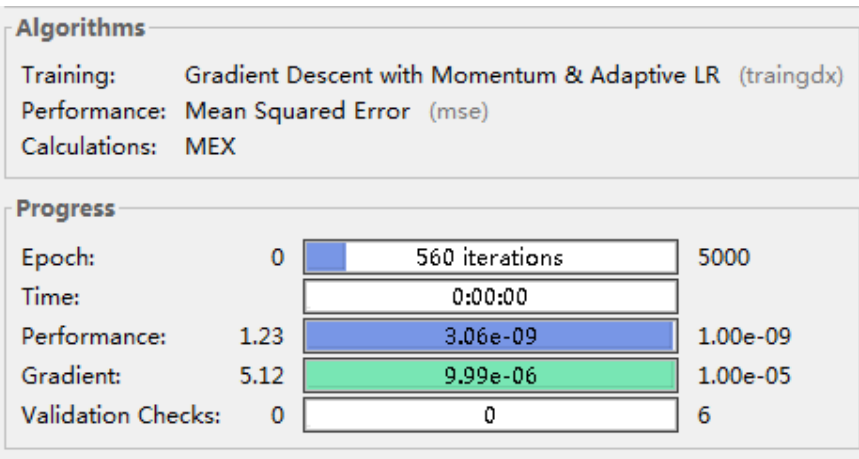

Figure 2: BP neural network training results show

The comparison between network training results and expert scores is shown in Figure 3. Among them, ' $O$ ' indicates expert score, and ' + ' indicates the result of network training. The network error curve figure 4 shows.

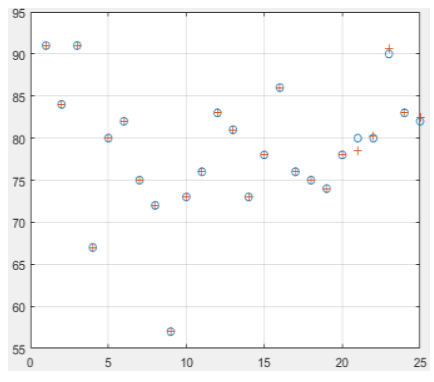

Figure 3: A comparison between training results

Figure 4: Expert scores and error change

Figure 5 shows that the mean square error of the network training is decreasing. When the network reaches the 560 step, the error value is $10^{-9}$.

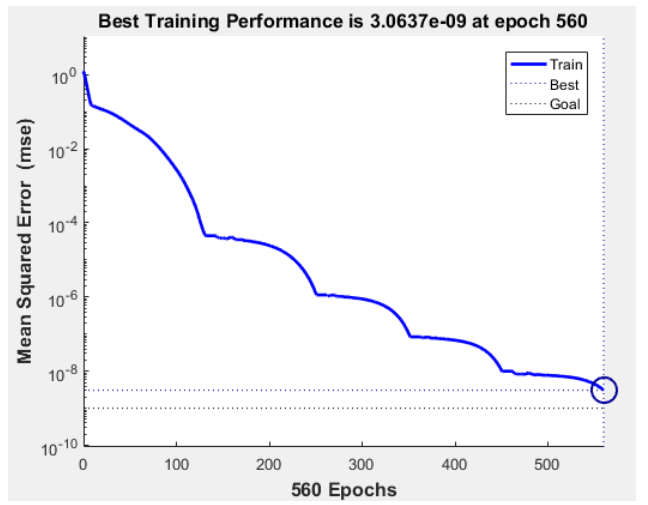

Figure 5: Mean squared error
The results of the network training are shown in Table 3. From the latter 5 sets of test data, we can see that the gap between network training results and expert scores is within acceptable limits. The range of error is between $[-0.045,1.557]$.

Table 3: Network training results

\begin{tabular}{|l|l|l|l|}
\hline Number & Experts score & $\begin{array}{l}\text { Training } \\
\text { score }\end{array}$ & Error \\
\hline 21 & 80 & 78.443 & 1.557 \\
\hline 22 & 80 & 80.271 & -0.271 \\
\hline 23 & 90 & 90.627 & -0.627 \\
\hline 24 & 83 & 83.045 & -0.045 \\
\hline 25 & 82 & 82.448 & -0.448 \\
\hline
\end{tabular}

The research results show that the application of BP neural network in the evaluation of students' examination can greatly reduce the time of evaluation work, overcome the subjective factors and enhance the scientificity, validity and rationality of the students' evaluation results. The model after training helps to evaluate the development of students and plays a significant role in regulating, controlling and promoting the two sides of teaching. It can provide a reasonable plan for students' examination and evaluation.

\section{CONCLUSION}

In this paper, there is a lot of optimization space. Through the application of genetic algorithm, fuzzy algorithm and other optimization algorithms, the stability and training precision of BP neural network can be improved, so that the training results are more applicable to the appraisal practice. In addition, selecting more and more representative training data is also helpful to improve the training effect of the network. This paper is based on a basic network model structure. In practical applications, the model can also be improved according to the specific requirements of evaluation, instead of manual to carry out more complex evaluation activities.

\section{ACKNOWLEDGMENTS}

Supported by Project of science and technology development fund of Tianjin City (20140818); Support ed by Foundation of Tianjin University of Technology and Education (KYQD13011).

\section{REFERENCES}

[1] Huang, G.Y. 2012. Education measurement and evaluation. Shanghai, East China Normal University Press.

[2] Peng, J.P. 2013. The research of the application of the BP neural network in teaching quality evaluation for national college. Gansu, Lanzhou University.

[3] Zhang, X.L., Min, J.Y. 2012. The Application of BP Neural Network in University Students' Comprehensive Quality Evaluation. The Fifth Annual Conference on educational reform and management engineering, Chongqing, 12, 29, 482-486.

[4] Ming Chen, M. 2013. The principle and practical example of MATLAB neural network. Beijing, Tsinghua university press. 